\title{
OVARIAN LIPIDS IN GUINEA-PIGS
}

\author{
D. P. SHARMA* AND T. A. VENKITASUBRAMANIAN
}

Vallabhbhai Patel Chest Institute, Delhi University, Delhi-7, India

(Received 30th May 1973)

An elevated level of phospholipids has been observed during the first half of pregnancy in sows (Bloor, Okey \& Corner, 1930; Boyd \& Eldon, 1935) and in rabbits (Morin, 1968), while guinea-pig ovaries were reported to contain $12.5 \mathrm{mg}$ phospholipids per $\mathrm{g}$ of tissue, and this level was maintained constant throughout early, mid- and late pregnancy (Boyd, 1935). No other report on guinea-pigs, giving details of ovarian lipid composition, incorporation studies and changes involved in pregnancy, appears to be available. This investigation was accordingly undertaken to elicit such information.

Female guinea-pigs of 5 to 6 months of age and in the 600- to 1000-g body wt range were selected at random. The experimental group was mated and maintained to mid-pregnancy while the control group was kept non-pregnant. Animals were injected intraperitoneally with $\left[1-{ }^{14} \mathrm{C}\right]$ acetate (sp.act. $3 \cdot 2 \mathrm{mCi}$ / $\mathrm{mmol}$ ) at the rate of $10 \mu \mathrm{Ci} / 100 \mathrm{~g}$ body wt, $2 \mathrm{hr}$ before autopsy, when the ovaries were removed and weighed to a precision of $0.01 \mathrm{mg}$. Extraction, fractionation by thin-layer chromatography, elution and estimations were carried out as reported elsewhere (Sharma \& Venkitasubramanian, 1973).

The ratio of ovarian weight (both ovaries) to body weight was $0.0166 \pm$ 0.0007 on the basis of six observations in mid-pregnancy against $0.0131 \pm$ 0.0006 in the controls. This elevated ratio was significant at $P<0.05$ and it reflected an increase in ovary weight during pregnancy.

The total lipids in mid-pregnancy increased by $16 \%$, phospholipids by $38 \%$ and total cholesterol by $11 \%$, though these changes were not found to be statistically significant (Table 1). When expressed in terms of $\mathrm{mg} /$ pair of ovaries, the total lipids were found to be significantly elevated. Increase in various lipids has been reported in sows (Bloor et al., 1930; Boyd \& Eldon, 1935) and in rabbits (Morin, 1968) during pregnancy. The percentage of phospholipids in total lipids was increased by $17 \%$ at the expense of glycerides, whereas cholesterol remained constant. Phosphatidyl choline and phosphatidyl ethanolamine were significantly elevated during pregnancy at the expense of other phospholipids. Morin (1968) also reported higher levels of phosphatidyl choline in pregnant rabbits. The percentage of triglycerides was significantly increased at the expense of monoglycerides. Incorporation studies with $\left[1-{ }^{14} \mathrm{C}\right]$ acetate showed that the specific activity of phosphatidyl ethanolamine was significantly reduced and no marked changes were observed in phosphatidyl choline during pregnancy. Total lipids also showed a trend towards a decreasing rate of

\footnotetext{
* Present address: Faculty of Agriculture, University of Dar es Salaam, c/o Post Box 643, Morogoro, Tanzania.
} 


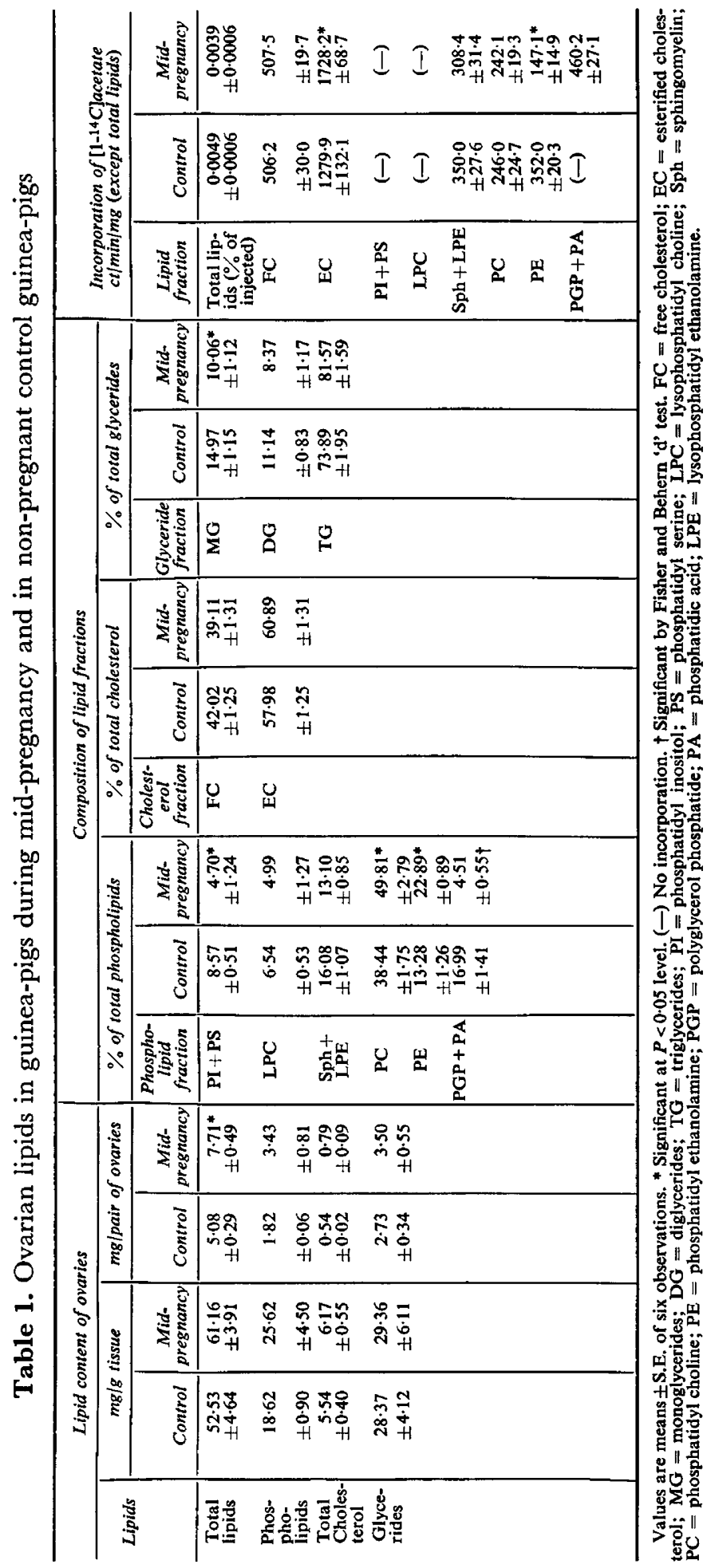


incorporation in experimental animals. This pointed to a reduced rate of lipid synthesis in general, and of phosphatidyl ethanolamine in particular, during pregnancy. The increased level of total lipids and various lipid fractions (Table 1), despite the diminished rate of their synthesis (incorporation studies), suggested reduced lipid utilization by the ovaries during pregnancy. The cholesterol ester, however, showed a significantly higher rate of incorporation indicating increased esterification of cholesterol, presumably for the purposes of transport of fatty acids during pregnancy.

\section{REFERENCES}

Bloor, W. R., OKEY, R. \& CoRneR, G. W. (1930) The relation of lipids to physiological activity. I. The changes in lipid content of corpus luteum of sow. 7. biol. Chem. 86, 291.

Boyd, E. M. (1935) The relation of lipid composition to physiological activity in the ovaries of pregnant and pseudo-pregnant rabbits. F. biol. Chem. 108, 607.

Boyd, E. M. \& ELDON, C. A. (1935) Relation of lipids to oestrin and progestin in corpus luteum of sow. Endocrinology, 19, 599.

MoRIN, R. J. (1968) Ovarian phospholipid composition and incorporation of $\left[1-{ }^{14} \mathrm{C}\right]$ acetate into the phospholipid fatty acids of ovaries from non-pregnant and pregnant rabbits. F. Reprod. Fert. 17, 111.

Sharma, D. P. \& Venkitasubramanian, T. A. (1973) Adrenal lipids in pregnancy. F. Reprod. Fert. 35, 195. 